\title{
Enabling Sustainable Organizational Change: A Case of Cognitive Diversity in the Automotive Industry
}

Tonja Blom, DBL

NWU Business School, North-West University, Potchefstroom, South Africa

(iD https://orcid.org/o0oo-0002-1903-6885

Yvonne du Plessis, $\mathrm{PhD}$

NWU Business School, North-West University, Potchefstroom, South Africa

(iD https://orcid.org/oooo-0002-6900-1664

Hamid H. Kazeroony, DM

NWU Business School, North-West University, Potchefstroom, South Africa

D https://orcid.org/oooo-0002-0961-1364

Contact: tonjablom@breede.co.za

\section{Abstract}

In diverse societies such as South Africa, organizations continue to face inclusion challenges when implementing change. This study proposes a different method and new dimension of diversity management within the cognitive diversity construct, namely human niche theory, to tackle the diversity dilemma of exclusivity. The research question asked whether human niche theory, as a defined concept within cognitive diversity, could be utilized by managers to enable inclusion and promote sustainable organizational change implementation. Conceptually, this paper relates human niche theory to seven themes in the change process, namely, communication, training, motivation, resources, control, monitoring, and feedback. An exploratory single case study in a multicultural South African automotive organization that implemented a company-wide technology change project was used as a unit of analysis. The single case study revealed a new understanding of change implementation processes using the human niche theoretical framework related to radical technological change implementation. Data collection included in-depth interviews, focus group sessions, solicited company data, field notes, and observations. Content and comparative data analysis were used to present findings. This research showed that managers' awareness of human niche theory in terms of cognitive diversity could assist in managing diversity, enabling inclusion, and change effectiveness in the organization, while minimizing emotional exclusion.

Keywords: change management, cognitive diversity, diversity management, human niche theory, humanistic, inclusion, multicultural

Date Submitted: May 21, 2021 | Date Published: November 24, 2021

\section{Recommended Citation}

Blom, T., du Plessis, Y., \& Kazeroony, H. (2021). Enabling sustainable organizational change: A case of cognitive diversity in the automotive industry. International Journal of Applied Management and Technology, 20, 143-166.

https://doi.org/10.5590/IJAMT.2021.20.1.08 


\section{Introduction}

Effective organizational change implementation often depends on how managers and employees understand the dynamics of diversity and inclusion. Globalization has brought diverse people together as exponential sociotechnical changes and conflicts present challenges (Marsella, 2009). The global environment is changing rapidly, and organizations must adopt and embrace relevant strategies to achieve stalwart success. (Choo et al., 2010). Marsella (2009) captured some of the many and complex diversity markers (e.g., ethnic, racial, age, gender, social class, and religion). However, the perceptions of diversity can complicate its dynamics as an organization undertakes change implementation (Marsella, 2009). These include perceptions of danger to survival, an unjust or unfair situation, competition for limited resources, and the availability of normal pathways for resolution (Marsella, 2009). Diversity not only accelerates change (Burke, 2009; Guillory, 2007) but can also be a critical driving force for change (Viljoen-Terblanche, 2008).

Post-1994, South Africa embarked upon a process of transformation that involved radical change implementation, of which one result was a shift in power relations between races (Booysen, 2007b). South African organizations, previously excluded, rapidly became part of the global business landscape (Dess \& Pickens, 2000; Hamel, 2002) with resultant complexities and requirements of reimagining themselves while aligning to the external environment (Nkomo \& Kriek, 2011) and local legislation. Adapting and understanding new identities became a crucial issue in South African organizations (Mare, 2005) which implied implementing change.

The organizational landscape continued to display racism and the different ways in which it was manifested (Mangcu, 2017), coupled with xenophobic violence (Andrucki, 2017). To complicate matters further, "in postapartheid South Africa, the greatest resistance to racial transformation has come mainly from white liberals and progressives" (Mangcu, 2017, p. 250). South African legislation typically requires organizations to utilize diversity markers (Marsella, 2009), which inevitably divides through race, ethnicity, gender, and age. Anciano (2016) found that the concept of nonracialism is deeply dividing and leads to racial categorization, disallowing organic development (ANC, 2005) of unity.

In South African organizations, misunderstandings and mistrust have become the norm amongst people. Long after the end of apartheid and despite various progressive legislative measures, for example, the Employment Equity Act (1998), the Promotion of Equality Act (1999), the Broad-Based Black Economic Empowerment Act (2003), and the Labour Relations Act (1995), we question whether diversity is harnessed to enable success or whether legislation merely assists with window dressing. We postulated that the use of complex diversity markers fosters segregation, resulting in division, us-versus-them attitudes, discord, dissonance, and disagreement, which hinders transformation, inclusion, and organizational success. Thus, South African organizations have continued to face challenges of inclusion when implementing change.

\section{Study Overview}

Modern technology, customer expectations, and increased diversity accelerate change, generally with extreme unpredictability (Burke, 2009; Guillory, 2007), while contributing to the need for organizations to modify the way they do things (Brown \& Eisenhardt, 1998). Individual, group, organizational and/or global diversity, as well as a combination of these, may influence organizational change implementation both negatively and positively. Diversity in organizations has been recognized as both a driving force and an obstacle for change. As a driving force, diversity promotes change in an organization to ensure equality, but as an obstacle, diversity brings along differences in behavior and thought, which requires management during the change implementation process (O'Donovan, 2018). Studies indicate that organizations struggle to sustain organizational change through optimizing diversity, as organizations mainly resort to a mechanistic approach 
by changing systems and procedures (e.g., Çavus et al., 2016; Liberman, 2013; Messeni Petruzzelli \& Rotolo, 2015) instead of realizing that sustainable change can occur only if people feel included, buy into the change, and renew their behavior accordingly.

The problem faced by organizations in managing change is that there is often a lack of inclusion at all levels, resulting in the absence of required participants. People ensure that organizational change happens as their attitudes and behaviors drive or stifle change. The people's niches-as described in terms of human niche theory (see Literature Review) - are mostly ignored in the change process, even more so if multicultural individuals and groups are employed in the organization.

The purpose of this study was to explore whether human niche theory can complement cognitive diversity in an organizational change initiative through inclusion and the creation of shared understanding. More specifically, we explored how change management and change implementation can be re-examined using human niche theory to minimize emotional exclusion within a change process in a multicultural organizational context such as South Africa. The primary research question was: Can the human niche theory, which derives from cognitive diversity in a uniquely African context, be utilized by management to enable inclusion, promote successful and sustainable organizational change implementation, and minimize emotional exclusion? This study deliberately moved away from traditional diversity markers such as ethnicity, race, and language and aimed to employ a more inclusive approach toward diversity management and a more inclusive and humane approach toward organizational change. Human niche theory can enable sustainable change while strengthening relationships through increasing trust and mutual understanding.

\section{Conceptual Framework}

Bond (2007) applied ecological theory to examine the nature of organizational change and the impact of diversity management on facilitating or hindering change. Other studies examined the nature of diversity management, and considered various sociological, psychological, ecological, and organizational frames, and how diversity influenced the nature of change, posing limitations, or facilitating its implementation (Barth \& Mahieu, 2011; Ewing, 2007; Guangming et al., 2003).

In this paper, we explore human niche theory as a lens through which cognitive diversity may be realized to promote successful organizational change. We utilized a cyclical adaptation of Kotter's (1996) eight-step linear change process, to evaluate human niche theory iteratively, as illustrated in Figure 1.

Figure 1. Cyclical and Circular Adaptation. Adapted from Kotter (1996) and Laubscher (2013).

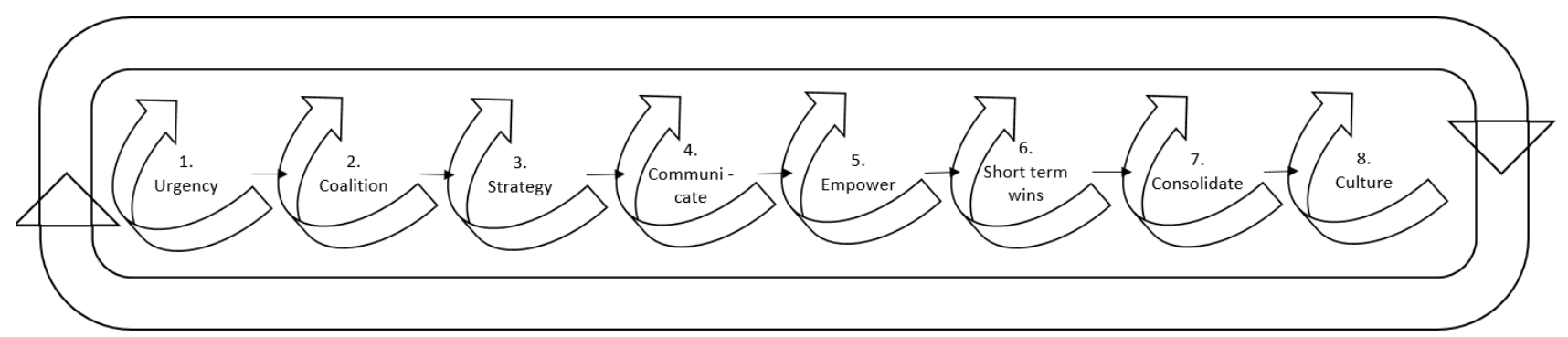

\section{Literature Review}

The difficulties related to organizational change interventions and the implementation thereof within a diverse workforce have seemingly not improved over the past couple of years. The purpose of the literature 
review was to explore diversity as a broader concept, as opposed to traditional views based on classifications such as race, ethnicity, gender, and age. As a result, literature related to diversity and inclusion, organizational change models, and human niches was searched to illuminate these difficulties, which continue to hamper successful organizational change implementation.

\section{Cognitive Diversity}

Diversity refers to "the distribution of differences among the members of a unit with respect to a common attribute" (Harrison \& Klein, 2007, p. 1200). Cognitive diversity is defined as "differences in beliefs and preferences held by upper echelon executives within a firm" (Miller et al., 1998, p. 41). Therefore, it follows that, "team members with different cognitions may pay attention to or extract different information about the same issue" (Schilpzand \& Martins, 2010, p. 2). Consequently, a variety of cognitions may be beneficial for completing tasks. Also, team members with different cognitions tend to consider different options in the decision-making process; thus, these teams have more solutions to the problem and can achieve better performance (Talke et al., 2010, p. 909). Liao and Long (2016) confirmed this, suggesting that "cognitive diversity has a significantly positive effect on team performance” (p. 217).

Chen et al. (2019) warned about the potential negative side of cognitive diversity, where cognitive diversity may become a double-edged sword that impacts innovative work behavior, while calling for future research to establish how diverse teams, composed of individuals with different cognitions, should be managed. These authors also warned about the dangers of emotional exclusion because of cognitive diversity. This requires an environment that shows support and encouragement to all employees.

Laubscher (2013) positioned human niche theory as a uniquely African contribution linked to cognitive diversity as defined by Miller (1990), Miller et al. (1998), and Schilpzand and Martins (2010), as it encompasses and clarifies the diversity of thought and behavior within a diverse team. Human niche theory allows management to recognize cognitive diversity to manage it effectively. Human niche theory will be discussed below.

\section{Diversity and Inclusion}

Daya (2014) confirmed that the extreme demographic misrepresentation of organizations remains a key business and societal issue in South Africa. Furthermore, Daya identified inclusion elements that need transformation at organizational, interpersonal, and individual levels. The researcher claimed that focus on these elements will help organizations move beyond employment equity compliance toward a committed multicultural, diverse, and inclusive organization (Daya, 2014).

Managing diversity in organizations is assumed to promote inclusion. McCarroll (2018) stated that the issue of diversity is addressed in single dimensions, where what is required is a multidimensional approach to creating workplaces where individuals trust and respect each other (regardless of gender, race, age, ethnicity, sexuality). Taking a linear approach to growing inclusivity will not yield diversity benefits (McCarroll, 2018). Bourke and Wakefield (2014) echo this, stating there is improvement needed in creating a culture for diversity and inclusiveness in organizations (Bourke \& Wakefield, 2014).

According to Plummer (2017), inclusion creates conditions that leverage differences-race, gender, age, job level, personality traits, thoughts and expression, and any other human and social differences. Plummer's research resulted in eight inclusion factors: shared purpose, trust, appreciation of individual attributes, sense of belonging, access to opportunity, equitable reward and recognition, cultural competence of the organization, and respect.

Booysen (2007a) and Moleke (2006) described an inclusive culture as an organization that values diversity, supports employment practices, creates an integrated human resource development and retention strategy, 
and identifies and manages capable talent. Viljoen-Terblanche (2008, p. 12) positioned inclusivity as a radical transformational methodology with the purpose to unleash the benefits of engagement and applied cognitive diversity. This systemic methodology aims at ensuring that everyone in the organization participates in the organizational strategy (the doing) and is involved in situations where individuals and groups can contribute their diverse gifts, talents, and thought processes (the being). However, in many organizations, inclusivity as within the diversity domain is not considered, especially when a change has to occur (Riordan, 2014). Managers often act exclusively, pushing their thoughts or a linear change process (e.g., Kotter, 1996) forward and thereby causing confusion, anxiety, and disengagement. Exclusivity is inherently opposite to inclusivity. We posit that exclusion and negative emotion are fed within a change process when cognitive diversity (as a continuum in the process) is not acknowledged and managed.

\section{Organizational Change Models}

Exploring diverse thinking and coping within a changing context is challenging as the majority of change models suggest a one-solution-fits-all approach (e.g., Kotter, 1996; Lewin, 1951; Tushman \& Romanelli, 1985). Many change models follow a mechanistic approach (e.g., Kotter, 1996; Lewin, 1951) while emphasizing a hard systems view as this underpins the traditional project definition (Crawford et al., 2003). However, this view is inadequate for dealing with ill-structured, real-world problems where defining clear objectives can be problematic (Yeo, 1993). A soft systems view requires increased situational understanding, thus engaging with people at a qualitative level. This implies seeing people as individuals, with their own culture and beliefs; then there are many possibilities for action, and each action is valued differently by different stakeholders (Checkland, 1999). This implies cognitive diversity.

In support of linear change models (e.g., Kotter, 1996; Lewin, 1951; Tushman \& Romanelli, 1985), various authors (e.g., Kübler-Ross, 1963; Scharmer, 2007; Viljoen-Terblanche, 2008) developed a more humanistic approach where emotional experiences during change are highlighted. Scharmer (2007) developed the Uprocess, which leads people through three core movements that allow them to connect to a changing future. The U-process acknowledges the voices of judgment, cynicism, and fear that hinder change and therefore require management (Scharmer, 2007). Kübler-Ross (1963) contributed to understanding the emotional experiences that are relevant in a change process: Her model normalizes emotions experienced during change (Viljoen-Terblanche, 2008). Viljoen-Terblanche (2008) adapted the work of Hopson and Adams (1966), Kübler-Ross, and Senge et al. (2004) to create an inclusivity framework. This framework depicts specific emotions as experienced during the different phases of change.

Although authors have included emotions, the impact of diversity and the resultant distress within an organizational change process are mostly omitted. Thus, the existing change models lack a multidimensional approach. To further complicate matters, most of what we know about organizational change is based on Western experiences and theories developed by studying large-scale change by leaders in European and American organizations (Bartlett \& Wozny, 2000; Ghoshal et al., 2002; Jick \& Peiperl, 2003; Nohria \& Beer, 2000).

Blom (2015) proposed a South African framework for change, which includes the individual, group, and organizational change process as well as various change elements. These change elements are visualized circularly and incorporate strategy, stress, and vicissitude while embracing ethics, understanding, reframed thoughts and methods, diversity, and regular conversations.

Although limited and prescriptive, the South African literature (Grobler, 1996; Luthans et al., 2004; McFarlin et al., 1999; Nkomo \& Kriek, 2004) points toward valuing diversity as a challenge to leading change (Leonardo \& Grobler, 2006; McFarlin et al., 1999). Further, existing change management approaches tend to oversimplify complex diversity constructs such as world views and value systems into diversity markers such as race, language, and gender. Given the emotional turmoil during the change, it seems as if a more 
humanistic perspective must be argued. In an attempt to consider these dilemmas, we explored the integration of human niches and organizational change management and implementation.

\section{Human Niches}

Colinvaux (1980) defined a niche as a specific set of capabilities for extracting resources, for surviving hazards, and for competing, coupled with a corresponding set of needs. However, this definition does not account for individual thinking patterns. According to Colinvaux, social unrest is necessary to change a niche (e.g., niches turned from hunter/gatherers to farmers/industrialists). Laubscher (2013) claimed that niches account for our thinking patterns: as niches change, new thinking patterns emerge, which lead to new realities.

Laubscher (2013) extended human niche theory in a uniquely African, diverse context. Although every niche is unique (Viljoen, 2016, Laubscher spoke of low and high human niche manifestations where "high exhibits a positive aspect of the niche and low describes a negative example of the niche" (p. 156). Owing to unconscious questions of existence, specific thinking systems-positioned as human niches-crystallize (Laubscher, 2013), resulting in one particular, existentialistic question that each niche asks.

Human niche theory (Laubscher, 2013) extends Graves's (1974) double-helix system, which emphasizes questions of existence and coping mechanisms in a uniquely African context. Helix I represents internal (e.g., genetic makeup, inherited characteristics, tendencies, and native intelligence) and external (e.g., the social and physical factors impinging on the individual or group that define the context in which choices are made) conditions of existence. Helix II represents coping methods, displayed as attitudes and behaviors in response to "why" questions.

Beck and Cowan (1996) assigned colors to each existential question. Table 1 depicts these colors against questions of existence (Laubscher, 2013). Thus, the beige human niche's existential question (diversity thought) is 'How will I survive?' and will excel at surviving against all the odds. Individuals, societies, and organizations value different things because of different thinking systems (Laubscher, 2013). The large dotted line in Table 1 indicates the area of focus of this paper. The two smaller dotted lines indicate the proposed focus of management (blue) and employees (purple). Blue asks how I can sacrifice to prepare for the future, and purple asks how I can sacrifice for the benefit of the community/family and/or elders.

Table 1. Human Niches and the Question of Existence, Resulting in Either Inclusion or Exclusion

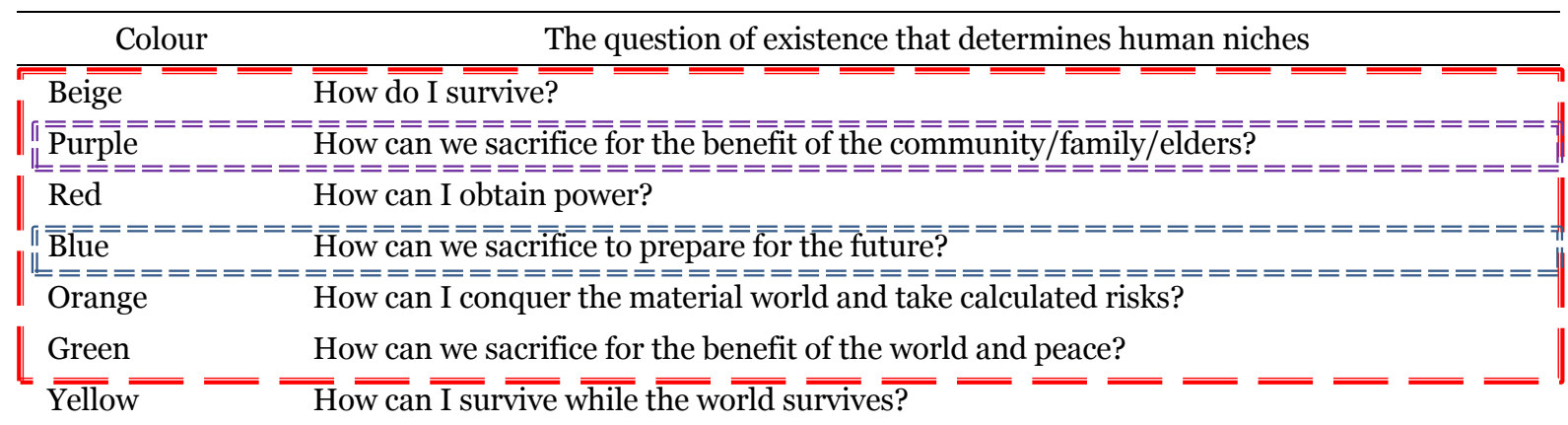

Note. From “Human Nature Prepares for a Momentous Leap," by C. W. Graves, 1974. Adapted by L. Laubscher, 2013, Human Niches-Spiral Dynamics for Africa.

Human niches are emerging waves and not rigid categories (Laubscher, 2013). Beck and Cowan (1996) see the different cultural human niches as cyclical and interactive, as well as linear and cumulative. A developmental stage cannot be skipped; therefore, as individuals, societies, and organizations move to a higher-order system, they transcend lower-level value systems (Dawlabani, 2013). 
The existential question of each human niche manifests in a unique organizing structure and principle. These principles of the human niches pertinent to this paper are displayed in Table 2. The worldviews depicted in Table 2 are characterized by fear (Crofts, 2008).

Table 2. The Belief/Value Structures and Their Respective Organizing Principles

\begin{tabular}{|c|c|c|}
\hline Organizing structure & $\begin{array}{c}\text { Organizational } \\
\text { principle }\end{array}$ & Behavioral principles \\
\hline \multicolumn{3}{|c|}{ Survival/Beige - Survival through sensory abilities } \\
\hline Band & \multirow[t]{4}{*}{ Instinct driven } & Survival driven and herd like \\
\hline & & Strong protect weaker members \\
\hline & & Group band together for mating and food gathering \\
\hline & & Herd-like structure changes format frequently \\
\hline \multicolumn{3}{|c|}{ Community/Purple-Interrelatedness, connection } \\
\hline Tribe & \multirow[t]{6}{*}{ Safety driven } & Circular tribal structure \\
\hline & & Led by elders \\
\hline & & Roles determined by kingship, sex, age, ancestry \\
\hline & & Rigid preservation of culture \\
\hline & & Custom demands obedience to elders/leaders \\
\hline & & Interrelatedness with each other and with nature \\
\hline \multicolumn{3}{|c|}{ Power/Red -Visible power display } \\
\hline Empire & \multirow[t]{5}{*}{ Power driven } & Power oriented, strongest only survive \\
\hline & & Expressive individualistic thinking which seeks attention \\
\hline & & Most powerful person makes decisions \\
\hline & & Big boss directs work bosses who drive the masses \\
\hline 64 of & & Downward communication \\
\hline \multicolumn{3}{|c|}{ Truth force/Blue-Absolute beliefs in one right way } \\
\hline Authority structure & \multirow[t]{8}{*}{ Order driven } & Rigid structure/rank rules \\
\hline & & Obedience to authority \\
\hline$\square$ & & Individuality sacrificed to the transcendent cause, truth, or \\
\hline$\square \square$ & & way \\
\hline ता ता ता ापा & & Guilt is used to impulsively control rewards \\
\hline & & Person with appropriate position an power makes decisions \\
\hline & & Divine authority speaks through secular authority \\
\hline & & Communication down and horizontally across classes \\
\hline \multicolumn{3}{|c|}{ Calculated risk/Orange-Success and status driven } \\
\hline Strategic enterprise & Success driven & Bureaucratic and status oriented \\
\hline & & Person with delegated authority makes decisions \\
\hline 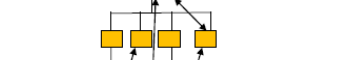 & & Distribution of specific amount of responsibilities \\
\hline 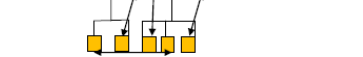 & & Communication down, up and across \\
\hline
\end{tabular}

Note. From The Crucible: Forging SA's Future, by Beck and Linscott, 1991. Adapted by T. Blom, 2015, in Fusing Organisational Change and Leadership Into a Practical Roadmap for South African Organisations. 


\section{Integration of Human Niches and Organizational Change}

Despite the investment in time and resources (Oakland \& Tanner, 2007), Kotter (1996) cautioned that most change initiatives have a low success rate. Organizational change is typically viewed as a linear and sequential process. Instead, change has revealed itself to be nonlinear and chaotic (Blom, 2015).

Although dated, Kotter (1996) provided a relevant theoretical base. However, when Kotter's work and that of Laubscher (2013) are overlaid, difficulties become evident. First, Kotter presented change as an eight-step linear process, whereas Laubscher (2013) and Viljoen-Terblance (2008) stated that change is cyclical and iterative. Second, Kotter's theory operates from a truth force/blue perspective; belief in one correct way as for a sacrifice for the future. Community/purple does not ask commercial questions; rather, it asks how it can sacrifice for the tribe. Power/red asks how it can gain power. If truth force/blue is not translated properly, community/purple will be driven away, and resistance will result (Laubscher, 2013; Viljoen, 2014). It seems that conflict will be inevitable when tribe or community, power and truth worldviews collide. This dysfunctional overlay is easily recognizable in Table 2.

Laubscher (2013) cautioned that $65 \%$ of people in Africa excel within the purple/community niche. Community/purple and power/red are, generally, not understood by truth force/blue. Truth force/blue organizations fail to understand why procedures and strategies are not implemented optimally.

Community/purple is nurtured through observing rituals, finding reassurance, and expressing a sense of enchantment in life's mystery (Laubscher, 2013; Viljoen, 2014). Power/red is excited by preserving stories of company heroes and celebrating feats of conquest, and by evidence of respect. Truth force/blue is reinforced through appeals to traditions, fair treatment for all, and by honouring length of service and loyalty.

Organizational change is inherently stressful (e.g., Blom, 2015; Dahl, 2009). Graves (1978) reiterated that stressed people are often driven by values different from those when they are relaxed. Laubscher (2013) confirmed this, stating that change will result in individuals regressing one level downwards. Hence, truth force/blue will drop to power/red, power/red will drop to community/purple and so forth. During change initiatives, individual stress increases, and we increasingly fail to understand each other. As a result, the benefits of cognitive diversity become lost.

\section{Case Study}

The backdrop of this case study was the automotive industry in South Africa. A large, bureaucratic manufacturing company ( $N=5,256$ employees) in South Africa, with a diverse employment composition, implemented a Total Working Time (TWT) technological system implementation to enable the measurement and improvement of labor efficiency. This diverse workforce comprised different genders, age groups, cultures, and levels of education.

At the onset of the project, Man-Hour-per-Unit (MHU) was used as an efficiency measurement tool and based on an ideal situation; assuming every employee spends 7.58 hours working. Such timing is unrealistic given nature breaks, training, and medical station visits. Utilizing an inaccurate MHU resulted in incorrect labor allocations. A more accurate calculation was needed to ensure optimal labor allocation. This radical change initiative and standard implementation would enable management to have real-time data available for decision making at the touch of a button. The data would account for every minute of employee time spent while in the production facility. Such data would assist in agile decision making in the global arena. The sensitive nature of the data, the impact on the human psyche when under constant observation and the possible implication when take-home-pay is affected was unsure and not considered.

The change initiative involved four manufacturing plants and required a change from the lowest 
organizational levels through to senior managers. This change affected five hierarchical levels. A further three hierarchical levels would utilize the collected data for strategic planning, human resource decisions, pay allocation, costing, and supply chain decisions. To illustrate, a senior manager would have numerous reporting section managers. Group leaders would report to one section manager. Group leaders are responsible for several team leaders who, in turn, are responsible for various team members. Team member, team leader, and group leader activities would be monitored to determine time spent away from the production line. These data would then be utilized for high-level decision making such as (a) hourly pay, (b) parts costs, and (c) some laborers required in each production process.

To realize this technological implementation, the objective of this technology project was to (a) expose and quantify inefficiencies that effect actual TWT, (b) design a system to capture and track actual TWT across all plants, (c) achieve optimal labor allocation through a true MHU calculation, and (d) to determine the average time per part assembly. This technology change would completely alter working data factors. The successful deployment, implementation, and daily use of this new system would thus depend heavily on the cooperation of this diverse workforce.

Breaking down the project-specific male/female demographics, those employees being affected by the change, indicates a dominant male profile (85\%), which is true in most manufacturing plants in South Africa. Structurally, team members report to team leaders and team leaders, in turn, report to group leaders.

\section{Resources}

In all, 224 group leaders were affected. Their international counterparts shadowed these group leaders, which meant that, daily, group leaders were followed, observed, taught, and monitored throughout the production process. Their international counterparts all spoke a different language and constituted a homogenous group.

\section{Training}

This technological change required daily capturing by group leaders. The amount of time spent by every team leader and team member had to be captured. Amount of time spent was to be indicated as absent, early out, late in, quality, training and/or time spent in the medical facility. The initial investigation indicated that less than half of the group leaders had previously used a personal computer. Thus group leader computer training was added to the project plan and resulted in a secondary project.

\section{Communication and Feedback}

A top-down communication approach was followed, which filtered information through various hierarchical levels. The communication function resided with the general manager of each production area given a large number of employees involved. The top-down line of communication followed the hierarchy from general manager to senior manager to section managers to group leaders to team leaders to team members. Ensuring correct communication through such a long line of communication proved challenging. Many employees felt the information was shared on a need-to-know basis. Rumours were common, and employees on the production line became withdrawn, quiet, inhibited, and unresponsive.

\section{Control and Monitor}

Time and attendance, absenteeism, leave, and general work methods are governed through the above topdown hierarchy. Similarly, punitive action due to noncompliance is meted out through this hierarchy. 


\section{Methodology and Research Design}

We adopted a single case study design to answer the research question. A case study is open to what emerges when the subject of inquiry is bound by its nature and dynamics and allows interpretation (Patton, 2015; Walsham, 1995). Despite its limitations for generalisability, the single case study provides a pathway to guide managers in change implementation (Leoni, 2015). It also allows for a richer and deeper understanding of dynamics in new empirical research areas (Hacklin \& Wallnöfer, 2012; Yin, 2018); such is the case in this study.

The population comprised all senior and middle managers who were part of the IT change implementation. We adopted a nonprobability purposive sample strategy in selecting the senior managers for in-depth interviews as well as middle managers for focus groups.

\section{Interview Guide}

We developed an interview guide for both the in-depth face-to-face interviews with senior managers and focus group discussions with middle managers. The questions we asked were aimed at gaining a deeper understanding of the actions managers took during a change, as well as how and why they took those actions, and at eliciting answers about possible links between human niches and change success. We asked the senior and middle managers similar questions, the only difference being the contextual lens. Senior management's perspective was more strategic, whereas the middle managers' perspective was more operational.

We asked participants about the change initiative and themes within change such as communication, training, feedback, leadership resources, control, and monitoring. The questions aimed to understand how miscommunication, misperception, and mistrust were helped or hindered within a change initiative. Also, during the in-depth interviews, we asked questions related to organizational change models, forces driving change, and change preparation. The interview guide included questions about how the individual coped with change, how well the change was understood, whether the individual was able to participate, and whether they received tools/help to empower them during the change process. Questions related to the role of leadership and which factors are critical to the success or detriment of the change initiative.

\section{Data Collection}

The data collection methods used were in-depth interviews, semistructured interviews in the form of focus group sessions, solicited company data, field notes, and observations. The in-depth interviews aimed to understand the concept of technological change as viewed by senior management. The focus groups explored the impact of technological change on employee performance. Minutes and project work documents were utilized to contextualize transactional work processes and the impact thereof on work performance. Observations in the workplace of employees' behaviors and activities provided an understanding of employee engagement (or not), productivity, attitude and work behavior about the technological change.

\section{Data Collection Process}

In-depth, open-ended question interviews were held with eight senior managers/leaders. The purpose of these interviews was to understand the role of leadership and the concept of organizational change as viewed through the eyes of senior leaders involved in strategic change initiatives. In-depth interviews lasted between 60 and 90 minutes and were recorded. We took notes during the interviews, jotting down prominent issues, subjects, and areas of focus. The interviews were transcribed within 5 days of the interview. A memo was written after each interview. If required, a follow-up meeting with the participant was arranged to ensure correctness and to clarify any items that required further elaboration. 
During four focus group sessions, we explored the impact of organizational change on middle management and aimed at understanding the role fulfilled by middle managers in change implementation. Each focus group session included seven employees from middle management. We selected these managers to participate based on the relevance of their involvement in technological change. All participants were directly involved in the execution of change initiatives. Each focus group session was conducted in an interactive group setting. The discussion format was semistructured, and when we asked questions, participants were free to engage with other group members. The focus group sessions mixed participants from various departments to ensure free participation. The sessions lasted between 50 and 60 minutes and were recorded. We transcribed these sessions within 5 days. A memo on the prominent issues and focus areas was written after each focus group session. If required, a follow-up meeting was arranged to ensure correctness and to clarify any items that required further elaboration. All focus group participants were involved in organizational change initiatives and, as such, focus group session questions related to the individual's experience within an organizational change initiative.

\section{Ethical Clearance}

We obtained ethical clearance before embarking on the research. All participants gave informed consent. We assured confidentiality and anonymity. Before the focus group sessions, the names of the participants were shared with other participants to ensure all parties were comfortable to share in the focus group sessions. It was repeatedly stated that participation was voluntary and withdrawal from the process was possible at any time.

\section{Data Analysis}

We utilized the premises of content and thematic analysis (Boyatzis, 1998), interview analysis (Kvale, 1996), and the use of open and axial coding. Qualitative data analysis may be a subjective process between the researchers, the data, and the interviewee, so we made every effort to manage possible biases. We reviewed each interview transcript and analysed sentence-by-sentence through consideration of unambiguous characteristics such as word frequencies. Each sentence was coded according to a concept. We grouped synonyms under an umbrella term for conceptualisation. Communication, information, announcements, contact, memo, and email were thus all classified under the umbrella term "communication." We developed a classification scheme from the concepts. An example of categories is displayed in Table 3. We further classified concepts as positive, negative, and neutral. We noted the frequency of each concept. This process was continually repeated allowing themes and patterns to emerge.

As Berg (1998) suggested, we continually compared the classification and reworked the scheme as the search for the same and other concepts continued line-by-line. We reviewed the emerging patterns to confirm understanding based on the results, as suggested by Patton 2015). We developed concepts into themes. We redrew the fractured data into relational maps to establish linkages between themes. We linked themes to theories. This approach allowed for the emergence of new possibilities when organizations are faced with change and a diverse workforce.

Table 3. Summary of Categories (Example)

\begin{tabular}{|c|c|c|}
\hline No. & Category & Identifier \\
\hline 1 & Communication & $\mathrm{P}_{4}, \mathrm{P}_{5}, \mathrm{P}_{6}, \mathrm{~F} 1, \mathrm{~F} 2, \mathrm{~F} 3, \mathrm{~F} 4, \mathrm{~F} 5, \mathrm{P}_{2} \mathrm{O}, \mathrm{P}_{17}, \mathrm{P}_{2}, \mathrm{C}_{1}, \mathrm{C}_{2}, \mathrm{C}_{3}$ \\
\hline 2 & Difficulty of change & $\mathrm{P}_{3}, \mathrm{P}_{5}, \mathrm{P} 6, \mathrm{C}_{1}, \mathrm{C}_{2}, \mathrm{C}_{3}$ \\
\hline 3 & Disempowerment & $\mathrm{F}_{1}, \mathrm{~F}_{2}, \mathrm{~F}_{4}, \mathrm{~F}_{3}, \mathrm{C}_{1}, \mathrm{C}_{2}, \mathrm{C}_{3}$ \\
\hline 4 & Resistance & $\mathrm{F}_{3}, \mathrm{~F} 1, \mathrm{~F}_{2}, \mathrm{~F}_{4}, \mathrm{P}_{20}, \mathrm{P}_{17}, \mathrm{P}_{4}, \mathrm{P}_{5}, \mathrm{P}_{1}, \mathrm{P}_{2}, \mathrm{C}_{1}, \mathrm{C}_{2}$ \\
\hline 5 & Understanding & $\mathrm{F}_{3}, \mathrm{~F}_{2}, \mathrm{~F}_{4}, \mathrm{~F}_{1}, \mathrm{P}_{4}, \mathrm{P}_{5}, \mathrm{P}_{2} \mathrm{O}, \mathrm{C}_{1}, \mathrm{C}_{2}, \mathrm{C}_{3}$ \\
\hline
\end{tabular}


The most prevalent interviewee responses to the change process and biographical data are set out in Table 4 . Given the large amount of data, only the most important data are indicated as evidence in Table 4. The prefix "P" represents individual interview data. The prefix " $F$ " represents focus group data. From these responses, change process themes emerged in relation to communication, training, motivation, resources, control, monitoring, and feedback.

Table 4. Interviewee Coding Data and Examples of Interviewee Responses

\begin{tabular}{|c|c|}
\hline Interviewee & Response-Evidence quotation \\
\hline & Communication \\
\hline \multirow[t]{4}{*}{ P2O } & Never announced the intention \\
\hline & Change was not properly explained \\
\hline & Letters are not communication \\
\hline & We need a new communication medium... communication is vital \\
\hline $\mathrm{P} 13$ & $\begin{array}{l}\text { We need communication throughout.... leadership must clearly communicate when discussing change ... } \\
\text { must clearly communicate what is coming }\end{array}$ \\
\hline $\mathrm{P}_{5}$ & $\begin{array}{l}\text { Communication with all stakeholders. Constant communication. Nobody knows what's happening. } \\
\text { Communication throughout the change process ... [to ensure] individual understanding. }\end{array}$ \\
\hline \multirow[t]{2}{*}{$\mathrm{P}_{4}$} & No effective communication method for thousands of employees. \\
\hline & Communication is a struggle.... explain why you are doing this. \\
\hline F3 & $\begin{array}{l}\text { Lack of communication contributes to resistance. Explanations are very vague. No one wants to } \\
\text { communicate. No communication from direct supervisor. }\end{array}$ \\
\hline \multirow[t]{2}{*}{ F2 } & Lack of communication. Problematic communication. Poor communication worsened the process. \\
\hline & Training \\
\hline F2 & Unsuitable training \\
\hline $\mathrm{F} 1$ & Shortcuts result in difficulties for followers. \\
\hline \multirow[t]{2}{*}{ F3 } & $\begin{array}{l}\text { Rotational training could have helped me ... understanding of employee and his/her job. Training will } \\
\text { improve understanding. There are always changes. We are unsure why the change was needed. We got } \\
\text { no training. }\end{array}$ \\
\hline & Motivation \\
\hline F2 & $\begin{array}{l}\text { No involvement. Involvement would be nice. I want to participate, but now [I am] unmotivated. } \\
\text { demotivated. }\end{array}$ \\
\hline F1 & Always need to do more with less ... no involvement in job function change ... [We are] unmotivated. \\
\hline & Change is a mess ... confusion ... conflict. \\
\hline & Resources \\
\hline F1 & $\begin{array}{l}\text { I don't understand change. Organizations avoid consultant costs ... results in problems. People must do } \\
\text { more with less.... increased expectation on staff, but no help or support.... organization could not support } \\
\text { the change internally. }\end{array}$ \\
\hline \multirow{3}{*}{$\begin{array}{l}\text { F2 } \\
\text { F3 }\end{array}$} & Change reduced my ability. I could not explain the change. \\
\hline & There was no help available. There was no resources ... no assistance. HR does not help change. \\
\hline & Control \\
\hline \multirow{4}{*}{$\begin{array}{l}\text { P20 } \\
\text { P13 } \\
P_{5}\end{array}$} & Productivity is always an issue. Involved management ... as change is chaotic. \\
\hline & Management does not show the end picture ... [I am] not sure why. \\
\hline & Strong management \\
\hline & How to make people understand ... need to know and understand staff in order to manage. \\
\hline
\end{tabular}




\begin{tabular}{|c|c|}
\hline P17 & $\begin{array}{l}\text { Business actions are [becoming] very short term ... needs [to] manage that change outcome is positive } \\
\text { not negative. }\end{array}$ \\
\hline $\mathrm{F} 1$ & $\begin{array}{l}\text { People don’t need micro-management. Increased autonomy is required. Organizations ... avoiding } \\
\text { change control. }\end{array}$ \\
\hline $\mathrm{F}_{3}$ & Management decides. Reduced autonomy results in change failure. \\
\hline & Monitoring \\
\hline $\mathrm{P}_{4}$ & We are forced to listen. Forced to behave.... force the vision through "army" \\
\hline $\mathrm{P}_{5}$ & See improvement quickly. \\
\hline F3 & $\begin{array}{l}\text { Change was all over the show.... no change preparation ... things are just done, no one understands why. } \\
\text { Messy change can't move the organization forward.... got no communication from [my] direct } \\
\text { supervisor. Supervisors should lead and guide the change, but this does not happen. }\end{array}$ \\
\hline & Feedback \\
\hline $\mathrm{P}_{5}$ & Can’t wait 3 years to give feedback to employees. \\
\hline P17 & Change must happen in a trustful environment, this requires feedback. \\
\hline $\mathrm{P} 13$ & $\begin{array}{l}\text { Info can't filter through because of friendships ... some people hear bits ... other know nothing ... } \\
\text { grapevine. }\end{array}$ \\
\hline F2 & Lack of feedback ... no feedback \\
\hline
\end{tabular}

The trustworthiness during data analysis was established through the retention of voice recordings, verification, and confirmation of transcripts with the interviewees.

\section{Limitations}

Although generalizable across industries, this single case study was drawn from one, large manufacturing organization in South Africa. The study did not aim to measure traditional diversity markers.

\section{Discussion and Findings}

In this section, we compare the change process in terms of cognitive diversity and will review how human niche theory was used as a diversity lens. We utilized and adapted Kotter's (1996) linear eight-step change process by linking human niche theory in an iterative manner through which seven core change themes emerged as pivotal in a multicultural change process where cognitive diversity is prevalent. We will discuss these core themes, namely, communication, training, motivation, resources, controlling, monitoring, and feedback, where each core theme is a process within a process, indicating how the utilization of different human niches may aid the individual and team change process. Lastly, we will review the new reality.

\section{Compared Change Process}

In this case study analysis, the results indicated that employees' need to understand, to participate, and to be engaged in change implementation process. Our findings contradict the mechanistic approach of many change models (e.g., Kotter, 1996; Lewin, 1951). Our results show that a top-down communication approach can hardly underpin the emotional stress related to such substantial changes to work procedures.

Oversimplification of complex, diverse values and emotional turmoil during change can easily result in a feeling of "us and them," which seems to fall back on mechanistic markers such as employees versus management, race, language, and rank. It seems inevitable that injecting a mechanistic process with turmoil and emotion will cause benefits of diversity and change, in general, to be lost. Following a linear process does not seem congruent with cyclical emotional turmoil, retrospective attitudes, and unity. 
We explored a more humanistic and inclusive approach, namely human niches. Table 5 illustrates the comparison extracted from the case study analysis about the change process, human niches, and change success. It also illustrates the incompatibility of cognitive diversity, as depicted by human niches, in the organization during periods of organizational change. We suggest, as shown in Table 5, the difficulty when following a one-solution-fits-all approach (e.g., Kotter, 1996; Lewin, 1951; Tushman \& Romanelli, 1985). The stress created by overlaying cognitive diversity without mutual understanding may result in resistance while unleashing the voices of judgement, cynicism, and fear (as per Scharmer \& Kaeufer, 2010).

Table 5. Comparison of Change Process and Human Niches as Experienced in the Case Study

\begin{tabular}{|c|c|c|c|c|c|}
\hline \multirow[t]{2}{*}{$\begin{array}{c}\text { Kotter's eight-step } \\
\text { model }\end{array}$} & \multirow[t]{2}{*}{$\begin{array}{c}\text { Change } \\
\text { process } \\
\text { implementing } \\
\text { success }\end{array}$} & \multirow[t]{2}{*}{$\begin{array}{c}\text { Change } \\
\text { experienced } \\
\text { by employees }\end{array}$} & \multicolumn{3}{|c|}{ Cognitive diversity (human niches) } \\
\hline & & & $\begin{array}{c}\text { Middle } \\
\text { management }\end{array}$ & $\begin{array}{c}\text { Senior } \\
\text { management }\end{array}$ & Employees \\
\hline $\begin{array}{l}\text { 1. Establish a sense of } \\
\text { urgency }\end{array}$ & 冈 & 冈 & red & orange/blue & purple \\
\hline $\begin{array}{l}\text { 2. Create a guiding } \\
\text { coalition }\end{array}$ & 冈 & 冈 & red & orange/blue & purple \\
\hline $\begin{array}{l}\text { 3. Develop a vision } \\
\text { and strategy }\end{array}$ & 冈 & 冈 & red & orange/blue & purple \\
\hline $\begin{array}{l}\text { 4. Communicate the } \\
\text { change vision }\end{array}$ & 冈 & 冈 & red & blue & purple \\
\hline $\begin{array}{l}\text { 5. Empower broad- } \\
\text { based action }\end{array}$ & 冈 & 冈 & red & blue & purple \\
\hline $\begin{array}{l}\text { 6. Generate short } \\
\text { term wins }\end{array}$ & 冈 & 冈 & red & red & red/purple \\
\hline $\begin{array}{l}\text { 7. Consolidate gains } \\
\text { and produce more } \\
\text { change }\end{array}$ & 冈 & 凶 & red & red & purple/beige \\
\hline $\begin{array}{l}\text { 8. Anchor new } \\
\text { approaches in the } \\
\text { corporate culture }\end{array}$ & 冈 & 凶 & red & red/blue & purple \\
\hline
\end{tabular}

Truth force/blue was the dominant human niche for middle and senior management. The case illustrated this as managers believed their way of doing things was the best and only way of doing things. Despite various struggles, managers could not change this belief system and continued doing more of the same with equally unsuccessful outcomes. The management's blue organizing principles were also displayed, where hierarchical levels of authority must be followed and respected, even when they do not serve a purpose or make sense.

In community/purple, the self is seen in relation to the collection, and everybody has equal opportunity to raise their issues, concerns, and viewpoints, but with an elder or leader who is responsible for the ultimate decision. However, community/purple was never given the opportunity to raise their issues and concerns, which created a disconnect between management and employees, paralysing or freezing community/purpleoriented employees. We postulate that managers who are linguistically versed in a "community/purple" manner of speech (e.g., metaphor or storytelling), should experience increased buy-in, reduced resistance, and improved change implementation. 
We continued to depict diversity, as displayed in the case study, against Kotter's traditional eight-step model. Even though dated, we used Kotter (1996) as this model is still the preferred choice in many organizations when changing. In the following section, we will compare Kotter's mechanistic approach against human niches.

\section{Step 1: Establish a Sense of Urgency}

If change is unnecessary, people will not buy into it or be willing to deal with it. Truth force/blue/management establishes a sense of urgency against a project plan. As some managers in the research stated, "We plan mechanistically," "A forward-thinking concept is correct," and "[we] work toward making the required change happen as quickly as possible." Community/purple/employees do not see past and present as opposites, rather as remote forms of the present. When this niche is unable to discuss, share opinions, and understand the reasoning, resistance and disconnect results. For example, some participants stated, "People don't know where they are expected to go," and "No buy-in will result in resistance." Management does not see the relevance of long discussions but will spend time post project completion on analysis and re-establishing relationships. Communication preference and perceived timeframes are different and when incognisant of this, management will struggle to establish a sense of urgency.

\section{Step 2: Create a Guiding Coalition}

The success of this project relied heavily on the cooperation of the employees at the lowest level in the organization. These employees, however, were not sufficiently consulted before the start of such a huge behavioral change initiative. In typical hierarchical fashion, truth force/blue/management believed that it had created a guiding coalition once a management meeting has been called and goals, tasks, and responsibilities shared. However, without the involvement of community/purple/employees, there is no guiding coalition from an employee perspective. Sabotage through resistance will result when the bigger picture is not understood by community/purple/employees. One particiant stated, "Organizations never announce their intentions" and "All should benefit through the change. This does not always happen".

\section{Step 3: Develop a Vision and Strategy}

Vision and strategy are set by truth force/blue/management which does not "speak" community/purple. As revealed by participants, management relates the need for change as "survival and competitiveness," "low productivity," and "some impending crisis." Community/purple expects management to live the vision and strategy, else they become despondent. One manager stated, "You should live the strategy. The opposite is true." If the vision and strategy fail in the betterment of all community/purple, another participant claimed, "I felt demotivated and disempowered," "I was uninvolved," and "I would have followed if I understood."

\section{Step 4: Communicate the Change Vision}

Truth force/blue/management communicates in a top-down, hierarchical manner. Management believes communication through memoranda, emails, notice boards and the like are sufficient and does not understand when employees say there is no communication. One manager justified this by stating, "Employees are being communicated to all the time, but they do not perceive communication to happen. Employees do not always recognise that they are communicating with them." Community/purple needs faceto-face, interactive communication where everybody is truly allowed to speak their minds, raise their opinion, and then allow the leader to make the ultimate decision, but this process takes time. As one manager stated, "Change is not a quick fix," "Letters and memos are not communication" and "Communication cannot be done haphazardly, you have to explain change ... [and] communicate.”

\section{Step 5: Empower Broad-Based Action}

Given the top-down, hierarchical fashion in which truth force/blue/management operates, broad-based empowerment is rarely realized. Truth force/blue/management expects respect for the position, which reduces the required effort to ensure understanding of the change initiative. As one manager stated, "We must empower people during the change. We don't.” As a result, employees (as representatives of 
community/purple) responded that "Employees must be involved" and that "There can be no change without trust. Trust does not just happen. Trust must be built. Involvement creates trust.”

\section{Step 6: Generate Short-Term Wins}

The project was constantly running behind schedule and management (truth force/blue human niche) continued to pressure departments, teams, and individuals to work harder and faster. There were no shortterm wins and no celebrations to ensure continued motivation. The unrelenting pressure increasingly stressed community/purple and amplified resistant behaviors. Employees felt paralysed and distressed, as evidenced by one participant's statement, claiming that "Employees resist due to already being stressed" and "There is too much change. The impact of stress on the organization is huge. The impact of stress is immeasurable." "I could not function at work because of stress. Change was very traumatic."

\section{Step 7: Consolidate Gains and Produce More Change}

This case study indicates an overwhelmingly large change with continued small changes. Truth force/blue/management pushed beyond realistic expectations. Without involvement, empowerment, and participation, it becomes challenging for lower-level employees to consolidate gains, understand whether they are moving forward or not, and continually produce more change while keeping a production plant operational. One partipant said, "I did not want to come to work because people expected answers from me and I had none."

\section{Step 8: Anchor New Approaches in the Corporate Culture}

In an ideal situation, despite difficulties and possible missed deadlines, employees should feel an overall sense of achievement within a change initiative. Achievement can then be anchored in the corporate culture, providing energy and motivation for the next round of change. Unfortunately, in this project, the overall feeling was one of failure and defeat that resulted in resistance and scepticism, which became anchored in the corporate culture.

Structural and cultural inertia, threats to existing power relationships, and threats to expertise and resource allocation hampered change. Poor implementation could be damaging, not easily reversible, and perpetuates scepticism. Community/purple, as confirmed by a participant, "fear and scepticism. Fear overrules all other emotions." The respondents agreed that, for as long as emotions such as fear, guilt, mistrust, rejection, false expectations, scepticism, and feelings of exclusions are predominant, individuals could not participate in the change effort.

\section{The New Reality}

Human niches are at work at an individual, team, and organizational level, which influences organizational outcomes as people value different things because they think differently. People may shift their thinking to fit the conditions at hand and will operate quite differently when under pressure or stress. Therefore, organizational change interventions should yield a multifaceted systemic approach as summarized in Table 6 . 
Table 6. Thematic Change Effectiveness, Human Niche, and Cognitive Diversity

\begin{tabular}{|c|c|c|c|c|}
\hline $\begin{array}{l}\text { Themes } \\
\text { identified }\end{array}$ & $\begin{array}{l}\text { Purple (preferred } \\
\text { method): } \\
\text { employees }\end{array}$ & $\begin{array}{l}\text { Blue (preferred } \\
\text { method): } \\
\text { management }\end{array}$ & Disconnect & $\begin{array}{l}\text { Improved change } \\
\text { though awareness of } \\
\text { cognitive diversity }\end{array}$ \\
\hline Communication & $\begin{array}{l}\text { Circular } \\
\text { Free opportunity to } \\
\text { raise opinions } \\
\text { 'Boss' makes final } \\
\text { decision } \\
\text { Involvement from start }\end{array}$ & $\begin{array}{l}\text { Top-down } \\
\text { Hierarchical } \\
\text { Communicate as } \\
\text { needed } \\
\text { No questioning }\end{array}$ & $\begin{array}{l}\text { Linear overlay over } \\
\text { circular preference }\end{array}$ & $\begin{array}{l}\text { Communication groups } \\
\text { Early involvement } \\
\text { Representatives to be } \\
\text { selected by employees }\end{array}$ \\
\hline Training & $\begin{array}{l}\text { Interactive } \\
\text { Kinaesthetic }\end{array}$ & $\begin{array}{l}\text { Bullet-points } \\
\text { Lecture style }\end{array}$ & $\begin{array}{l}\text { Linear overlay over } \\
\text { kinaesthetic } \\
\text { preference }\end{array}$ & $\begin{array}{l}\text { Interactive training } \\
\text { Venue (noise, movement, } \\
\text { singing) } \\
\text { Timeous and allow for } \\
\text { re-training }\end{array}$ \\
\hline $\begin{array}{l}\text { Motivation and } \\
\text { leadership }\end{array}$ & $\begin{array}{l}\text { Collective determines } \\
\text { leadership } \\
\text { Good of the collective } \\
\text { motivates }\end{array}$ & $\begin{array}{l}\text { Position requires } \\
\text { authority } \\
\text { Position delegates }\end{array}$ & $\begin{array}{l}\text { Formal } \\
\text { leader/position } \\
\text { holder not necessarily } \\
\text { regarded as such }\end{array}$ & $\begin{array}{l}\text { Ensure early involvement } \\
\text { from informal leader }\end{array}$ \\
\hline Resources & $\begin{array}{l}\text { Resources must be } \\
\text { utilized for the } \\
\text { betterment of all }\end{array}$ & $\begin{array}{l}\text { Resources utilized to } \\
\text { increase profit }\end{array}$ & $\begin{array}{l}\text { Disparate beliefs } \\
\text { regarding resource } \\
\text { utilization }\end{array}$ & $\begin{array}{l}\text { Joint agreement on } \\
\text { utilization-increased } \\
\text { profits and increased } \\
\text { community benefit }\end{array}$ \\
\hline Controlling & $\begin{array}{l}\text { Informal leader } \\
\text { controls and makes } \\
\text { decisions }\end{array}$ & $\begin{array}{l}\text { Control vested in } \\
\text { organizational } \\
\text { structure and } \\
\text { positions of power }\end{array}$ & $\begin{array}{l}\text { Control by formal } \\
\text { leader/position } \\
\text { holder not necessarily } \\
\text { regarded }\end{array}$ & $\begin{array}{l}\text { Empower informal } \\
\text { leader to control aspects } \\
\text { of the project }\end{array}$ \\
\hline Monitoring & $\begin{array}{l}\text { Informal leader may } \\
\text { monitor collective. } \\
\text { "Outside" leader } \\
\text { cannot impact on } \\
\text { collective behavior }\end{array}$ & $\begin{array}{l}\text { Monitoring vested in } \\
\text { organizational } \\
\text { structure and } \\
\text { positions of power }\end{array}$ & $\begin{array}{l}\text { Monitoring by formal } \\
\text { leader/position } \\
\text { holder not necessarily } \\
\text { regarded }\end{array}$ & $\begin{array}{l}\text { Empower informal } \\
\text { leader to monitor aspects } \\
\text { of the project }\end{array}$ \\
\hline Feedback & $\begin{array}{l}\text { Collective discussions } \\
\text { with feedback to } \\
\text { informal leader }\end{array}$ & $\begin{array}{l}\text { Feedback on "need } \\
\text { to know" basis }\end{array}$ & $\begin{array}{l}\text { "Need to know" } \\
\text { feedback results in } \\
\text { disconnect, feeling } \\
\text { uninvolved and } \\
\text { disinterested }\end{array}$ & $\begin{array}{l}\text { Continuous, interactive } \\
\text { feedback. Taking and } \\
\text { applying comments } \\
\text { seriously (careful not to } \\
\text { window dress comments) }\end{array}$ \\
\hline
\end{tabular}

Our research showed that different human niches, as a cognitive diversity lens, were not understood or applied throughout the change process within the case that we studied. Hence, unintended failures, unforeseen implications, and general difficulties arose. Ideas that fell outside the norms and assumptions were often rejected without consideration. As a rule, individuals with different thinking systems also look upon behaviors of other human niches and do not understand what they see. Even more pertinently, during times of organizational change, translation between different niches becomes imperative.

Such cognitive diversity requires that Kotter's (1996) eight-step model be applied as a cyclical and reiterative process. Considering different human niches in the change process opens the possibility of more sustainable 
change. Redoing the case study themes by applying traditional management functions through a human niche lens could then represent a different reality.

It seems as if cognitive diversity, applied through a human niche theoretical lens, may enable and promote successful organizational change implementation. The application of human niches may assist not only in improving understanding but also in supporting the relevant adaptation of communication, training, leadership, and management as well as feedback methodologies and functions. Figure 2 illustrates the need to acknowledge cognitive diversity, as displayed through human niches, within a change initiative.

Figure 2. New Reality: Case Study Themes, Circular Application

\begin{tabular}{|c|c|c|c|}
\hline \multicolumn{4}{|c|}{ Cognitive diversity (Human niches) } \\
\hline Kotter's eight-step model & Middle management & Senior management & Employees \\
\hline 1. Establish a sense of urgency & & & \\
\hline 2. Create a guiding coalition & & & \\
\hline 3. Develop a vision and strategy & & & \\
\hline 4. Communicate the change vision & & & \\
\hline 5. Empower broad-based action & & & \\
\hline 6. Generate short term wins & & & \\
\hline $\begin{array}{l}\text { 7. Consolidate gains and produce } \\
\text { more change }\end{array}$ & & & \\
\hline $\begin{array}{l}\text { 8. Anchor new approaches in the } \\
\text { corporate culture }\end{array}$ & & & \\
\hline
\end{tabular}

Figure 2 illustrated the need for circular and reiterative thinking and circular processes as opposed to linear and sequential. Further, the figure illustrates the iterative requirement of circular processes as indicated by the four arrows inside the center.

\section{Managerial Implications}

Employees have a deep need for communication and involvement. Management that communicates effectively and involves employees creates the potential to motivate various aspects of their performance. Utilizing the knowledge of cognitive diversity enables management to adapt communication strategies according to employee needs. Management that knows their employees will thus ensure face-to-face contact when communicating with purple while utilizing emails and memos when communicating with blue employees. Such small changes to the communication process can be very powerful to empower employees to join in conversations.

Similarly, an understanding of cognitive diversity will enable management to be more effective throughout the entire change process. Human niches allow for the creation of an environment where interaction, understanding, and trust can develop. Within such an environment, resistance can be minimized, and change optimized. Utilizing human niches to ensure effective communication can largely assist organizations in taking up the global challenge in a more effectual manner.

Managers who are aware and well versed in cognitive diversity, as manifested in niches, can foster inclusion, 
as opposed to exclusion and misunderstanding. Further, managers who can adopt a more humanistic approach, seeing and understanding people as unique with their own diversity of thought and worldviews, could better allow change implementation by enhancing the possibilities for action during organizational change. Utilizing human niche theory may guide management toward greater change success.

\section{Conclusion Recommendations and Significance}

Although an understanding of human niches may assist organizations with change initiatives, the reality of different niches at play is not integrated into traditional organizational change literature. This research revealed how human niche theory could be used as a lens through which cognitive diversity would enable and promote successful organizational change, namely through (a) adapting communication methods, (b) clearer translation of organizational objectives, (c) shared understanding of each other, (d) ensuring wide participation as opposed to exclusion, and (e) the reality of multidimensional solutions. This case illustrated the reality of human emotions during change and the impact of heightened stress, bringing an awareness of the behavioral modifications needed to navigate difficulties and negativity during change initiatives.

Human niche theory provides organizational leaders with a lens through which the impact of change on individuals can be better understood. In organizations where change is prevalent, a primary challenge is to communicate effectively to all employees to optimise human behavior. Through the application of human niche theory, organizations could be assisted in developing more than one strategy to improve the effectiveness of communication, training, motivation, leadership, resources, control, monitoring, and feedback during times of organizational change. Integrating cognitive diversity into a cyclical change process may enable and enhance change implementation effectiveness.

Human niche theory presents a dimension of diversity management, namely that it advances cognitive diversity, in the process steering away from stereotypical diversity markers such as ethnicity, race, and language. Human niche theory also embodies a possible means through which cognitive diversity could enable the successful implementation of organizational change.

In our final contribution, following the thinking of Laubscher (2013), we postulate that most managers, due to their training and development, think in a particular manner (linear and Newtonian thinking or blue) while most employees in an African and collective context think in a more circular, fluid, and interactive manner (purple). A lack of understanding related to such cognitive diversity would probably cause misunderstanding, conflict, and unsuccessful change. 


\section{References}

African National Congress. (2005, June 29). The National Question [Discussion document]. 2nd National General Council, Tshwane, South Africa. https://new.anc1912.org.za/2nd-ngc-discussion-documentthe-national-question/

Anciano, F. (2016). A dying ideal: Non-racialism and political parties in post-apartheid South Africa. Journal of Southern African Studies, 42(2), 195-214. https://doi.org/10.1080/03057070.2016.1152090

Andrucki, M. J. (2017). Wish you were here: Bodies, diaspora strategy and the politics of propinquity in postapartheid South Africa. The Geographical Journal, 183(1), 47-57. https://doi.org/10.1111/geoj.12189

Barth, I., \& Mahieu, C. (2011). Diversity management and organizational change: Potentialities and limitations. International Journal of Diversity in Organizations, Communities \& Nations, 11(1), 105116. https://doi.org/10.18848/1447-9532/cgp/v11io1/38967

Bartlett, C. A., \& Wozny, M. (2000). GE's two-decade transformation: Jack Welch's leadership. Harvard Business School.

Beck, D. E., \& Cowan, C. C. (1996). Spiral dynamics: Mastering values, leadership and change. Blackwell Publishers.

Beck, D. E., \& Linscott, G. (1991). The crucible: Forging SA's future, New Paradigm Press.

Berg, B. L. (1998). Qualitative research method 7 for the social sciences (3rd ed.). Allyn \& Bacon.

Blom, T. (2015). Fusing organisational change and leadership into a practical roadmap for South African organisations [Doctoral thesis, University of South Africa]. Unisa Institutional Repository. https://uir.unisa.ac.za/bitstream/handle/10500/20151/thesis_blom_t.pdf?sequence=1\&isAllowed=y

Bond, M. A. (2007). Workplace chemistry: Promoting diversity through organizational change. University Press of New England.

Booysen, L. (2007a). Barriers to employment equity implementation and retention of Blacks in management in South Africa. South African Journal of Labour Relations, 31(1), 47-70.

Booysen, L. (2007b). Societal power shifts and changing identities in South Africa: Workplace implications. South African Journal of Economic and Management Sciences, 1O(1), 1-17. https://doi.org/10.4102/sajems.v10i1.533

Bourke, J., Stockton, H., \& Wakefield, N. (2014). From diversity to inclusion: Move from compliance to diversity as a business strategy. Deloitte Insights. https://www2.deloitte.com/us/en/insights/focus/human-capital-trends/2014/hc-trends-2014diversity-to-inclusion.html

Boyatzis, R. E. (1998). Transforming qualitative information: Thematic analysis and code development. SAGE.

Broad-Based Black Economic Empowerment Act 2003. (2004, January 9). Government Gazette. Republic of South Africa. https://www.gov.za/sites/default/files/gcis_document/201409/a53-030.pdf

Brown, S. L., \& Eisenhardt, K. M. (1998). Competing on the edge: Strategy as structured chaos. Harvard Business School Press.

Burke, W. W. (2009). Understanding organizations: The process of diagnosis. In W. W. Burke, D. G. Lake, \& J. W. Paine (Eds.), Organization change: A comprehensive reader (pp. 259-272). Jossey-Bass.

Çavus, M. F., Kapusuz, A. G., \& Bicer, M. (2016). Perceptions of diversity management and alienation in multinational companies. Journal of Academic Research in Economics, 8(2), 252-268. 
Checkland, P. (1999). Soft systems methodology: A 30-year retrospective. In P. Checkland \& J. Scholes (Eds.), Soft systems methodology in action. Wiley.

Chen, X., Liu, J., Zhang, H., \& Kwan, H. K. (2019). Cognitive diversity and innovative work behaviour: The mediating roles of task reflexivity and relationship conflict and the moderating role of perceived support. Journal of Occupational and Organizational Psychology, 92(3), 671-694. https://doi.org/10.1111/joop.12259

Choo, S. S., Halim, H., \& Keng-Howe, I. C. (2010). The impact of globalisation on strategic human resources management: The mediating role of CEO in HR. International Journal of Business Studies, 18(1), 101-124.

Colinvaux, P. (1980). The fate of nations: A biological theory of history. Simon and Schuster.

Crawford, L., Costello, K., Pollack, J., \& Bentley, L. (2003). Managing soft change projects in the public sector. International Journal of Project Management, 21(6), 443-448. https://doi.org/10.1016/so2637863(02)00099-6

Crofts, N. (2008, June 30). Spiral dynamics-A map of the evolution of human consciousness. The Magic of Being. http://themagicofbeing.squarespace.com/spiral-dynamics

Dahl, M. S. (2009, May 21-23). The cancer of organizational change [Paper presentation]. European Meeting on Applied Evolutionary Economics, Jena, Germany.

Dawlabani, S. (2013). MEMEnomics: The next generation economic system. Select Books.

Daya, P. (2014). Diversity and inclusion in an emerging market context. Equality, Diversity and Inclusion, 33(3), 293-308. https://doi.org/10.1108/edi-10-2012-0087

Dess, G., \& Pickens, J. (2000). Changing roles: Leadership in the 21st century. Organizational Dynamics, Winter, 18-33. https://doi.org/10.1016/Soo9o-2616(00)88447-8

Employment Equity Act 1998. (1998, October 19). Government Gazette. Republic of South Africa. https://www.gov.za/sites/default/files/gcis_document/201409/a55-980.pdf

Ewing, A. K. (2007). Consideration of change and diversity in an organizational planning effort: A report on the strategic planning initiative for the association for applied psychophysiology and biofeedback. Biofeedback, 35(1), 8-12.

Ghoshal, S., Gratton, L., \& Rogan, M. (2002). The transformation of BP. London Business School.

Graves, C. W. (1974, April). Human nature prepares for a momentous leap. The Futurist, 72-87.

Graves, C. W. (1978). Up the existential staircase: Seminar on the development, nature, meaning and management of the levels of existence, emergent, cyclical, double helix model of adult human psychosocial coping systems [1978/same paper with graphs added 1980, seminar in Dallas], 1974. Seminar sponsored by the National Values Center, Washington, DC].

Grobler, P. A. (1996). In search of excellence: Leadership challenges facing companies in South Africa. SAM: Advanced Management Journal, 61(2), 22-34.

Guangming, C., Clarke, S., \& Lehaney, B. (2003). Diversity management in organizational change: Towards a systemic framework. Systems Research \& Behavioral Science, 2O(3), 231-242. https://doi.org/10.1002/sres.530

Guillory, W. A. (2007). The future perfect organization: Leadership for the twenty-first century-Part I. Industrial and Commercial Training, 39(1), 52-58. https://doi.org/10.1108/00197850710721408 
Hacklin, F., \& Wallnöfer, M. (2012). The business model in the practice of strategic decision making: Insights from a case study. Management Decision, 5o(2), 166-188.

https://doi.org/10.1108/00251741211203515

Hamel, G. (2002). Leading the revolution. Harvard Business School Press.

Harrison, D. A., \& Klein, K. J. (2007). What's the difference? Diversity constructs as separation, variety, or disparity in organizations. Academy of Management Review, 32(4), 1199-1228. https://doi.org/10.5465/amr.2007.26586096

Hopson, B., \& Adams, J. (1966). Towards an understanding: Defining some boundaries of transition dynamics. In J. Adams, J. Hayes, \& B. Hopson (Eds.), Transition: Understanding and managing personal change. Martin Robertson.

Jick, T., \& Peiperl, M. A. (2003). Managing change: Cases and concepts. McGraw-Hill.

Kotter, J. P. (1996). Leading change. Harvard Business School Press.

Kübler-Ross, E. (1963). On death and dying. MacMillan.

Kvale, S. (1996). Interviews: An introduction to qualitative research interviewing. SAGE.

Labour Relations Act 1995. (1995, December 13). Office of the President (South Africa). https://www.gov.za/sites/default/files/gcis_document/201409/act66-1995labourrelations.pdf

Laubscher, L. (2013). Human niches-Spiral dynamics for Africa [Unpublished doctoral dissertation]. The Da Vinci Institute for Technology Management.

Leonardo, A., \& Grobler, A. F. (2006). Exploring challenges to transformational leadership communication about employment equity: Managing organizational change in South Africa. Journal of Communication Management, 10(4), 390-406. https://doi.org/10.1108/13632540610714827

Leoni, L. (2015). Adding service means adding knowledge: An inductive single-case study. Business Process Management Journal, 21(3), 610-627. https://doi.org/10.1108/bpmj-07-2014-0063

Lewin, K. (1951). Field theory in social science. Harper and Row.

Liao, Z., \& Long, S. (2016). Cognitive diversity, alertness, and team performance. Social Behaviour and Personality, 44(2), 209-220. https://doi.org/10.2224/sbp.2016.44.2.209

Liberman, B. E. (2013). Eliminating discrimination in organizations: The role of organizational strategy for diversity management. Industrial and Organizational Psychology: Perspectives on Science and Practice, 6(4), 466-471. https://doi.org/10.1111/iops.12086

Luthans, F., Van Wyk, R., \& Walumbwa, R. (2004). Recognition and development: Hope for South African organizational leaders. Leadership and Organization Development Journal, 25(6), 512-527. https://doi.org/10.1108/01437730410556752

Mangcu, X. (2017). South Africa and the United States: Notes toward an anti-racist vision. Brown Journal of World Affairs, 23(2), 239-252.

Mare, G. (2005). Race, nation, democracy: Questioning patriotism in the new South Africa. Social Research, $72,501-532$.

Marsella, A. J. (2009). Diversity in a global era: The context and consequences of differences. Counselling Psychology Quarterly, 22(1), 119-135. https://doi.org/10.1080/09515070902781535

McCarroll, J. (2018, September). Flexibility, inclusivity and a sense of purpose. NZ Business and Management, 32(8), 18-19. https://management.co.nz/magazine-issue/management-september2018 
McFarlin, S., Coster, E., \& Mogale-Pretorius, T. (1999). South African management development in the 21st century: Moving towards an Africanized model. Journal of Management Development, 18, 63-77. https://doi.org/10.1108/02621719910250474

Messeni Petruzzelli, A., \& Rotolo, D. (2015). Institutional diversity, internal search behaviour, and jointinnovations. Management Decision, 53(9), 2088-2106. https://doi.org/10.1108/MD-05-2014-0256

Miller, C. C. (1990). Cognitive diversity within management teams: Implications for strategic decision processes and organizational performance [Unpublished doctoral dissertation]. University of Texas.

Miller, C. C., Burke, L. M., \& Glick, W. H. (1998). Cognitive diversity among upper-echelon executives: Implications for strategic decision processes. Strategic Management Journal, 19(1), 39-58. https://doi.org/10.1002/(sici)1097-0266(199801)19:1\%3C39::aid-smj932\%3E3.o.co;2-a

Moleke, P. (2006). After 10 years of employment equity, it's still business as usual. HSRC Review, 4(1), 4-5.

Nkomo, S. M., \& Kriek, D. (2011). Leading organizational change in the "new" South Africa. Journal of Occupational and Organizational Psychology, 84(3), 453-470. https://doi.org/10.1111/j.20448325.2011.02020.x

Nkomo, S. M., \& Kriek, H. S. (2004). Leading transformational change: Challenges and opportunities. In T. Meyer \& I. Boninelli (Eds.), Conversations in leadership: A South African perspective (pp. 84-106). Knowledge Resources.

Nohria, N., \& Beer, M. (2000). Cracking the code of change. Harvard Business School Press.

Oakland, J. S., \& Tanner, S. J. (2007). A new framework for managing change. The TQM Magazine, 19(6), 572-589. https://doi.org/10.1108/09544780710828421

O’Donovan, D. (2018). Diversity and inclusion in the workplace. In C. Machado \& J. P. Davim (Eds.), Organizational behaviour and human resource management: A guide to a specialized MBA course (pp. 73-108). https://doi.org/10.1007/978-3-319-66864-2_4

Patton, M. Q. (2015). Qualitative research \& evaluation methods: Integrating theory and practice (4th ed.). SAGE Publications.

Plummer, D. L. (2017, July 10). Getting to we: Inclusion is more than a feeling. HuffPost. https://www.huffpost.com/entry/getting-to-we-inclusion-is-more-than-afeeling_b_5963ae96e4bo9be68c00545b

Promotion of Equality and Prevention of Unfair Discrimination Bill. (1999, October 25). Government Gazette. Republic of South Africa. https://www.gov.za/sites/default/files/gcis_document/201409/b57-99.pdf

Riordan, C. M. (2014, June 5). Diversity is useless without inclusivity. Harvard Business Review. https://hbr.org/2014/o6/diversity-is-useless-without-inclusivity

Scharmer, O. C. (2007). Theory U: leading from the future as it emerges. Society of Organizational Learning.

Scharmer, O. C., \& Kaeufer, K. (2010). In front of the blank canvas: Sensing emerging futures. Journal of Business Strategy, 31(4), 21-29. https://doi.org/10.1108/02756661011055159

Schilpzand, M. C., \& Martins, L. L. (2010). Cognitive diversity and team performance: The roles of team mental models and information processing. Academy of Management Proceedings, 2010(1), 1-6. http://doi.org/crxjgb

Senge, P. M., Scharmer, C. O., Jaworski, J., \& Flowers, B. S. (2004). Presence: Human purpose and the field of the future. Society for Organizational Learning. 
Talke, K., Salomo, S., \& Rost, K. (2010). How top management team diversity affects innovativeness and performance via the strategic choice to focus on innovation fields. Research Policy, 39(7), 907-918. http://doi.org/brchpk

Tushman, M. L., \& Romanelli, E. (1985). Organizational evolution: A metamorphosis model of convergence and reorientation. Research in Organizational Behavior, 7, 171-222.

Viljoen, R. (2016). Inclusive organizational transformation: An African perspective on human niches and diversity of thought. Routledge.

Viljoen-Terblanche, R. C. (2008). Sustainable organisational transformation through inclusivity [Doctoral dissertation, University of South Africa]. Unisa Institutional Repository. https://uir.unisa.ac.za/bitstream/handle/10500/726/oothesis.pdf?sequence=2\&isAllowed=y

Walsham, G., (1995). Interpretive case studies in IS research: Nature and method. European Journal of Information Systems, 4(2), 74-81. https://doi.org/10.1057/ejis.1995.9

Yeo, K. T. (1993). Systems thinking and project management-time to reunite. International Journal of Project Management, 11(2),111-7. https://doi.org/10.1016/0263-7863(93)90019-j

Yin, R. K. (2018). Case study research and applications: Design and methods (6th ed.). SAGE.

The International Journal of Applied Management and Technology (IJAMT), sponsored by Walden University's College of Management and Technology, is a peer-reviewed, online journal that addresses contemporary national and international issues related to management and technology. 